\title{
Clinical and experimental approaches to knee cartilage lesion repair and mesenchymal stem cell chondrocyte differentiation
}

\author{
Fredy Montoya 1,3\#, Fernando Martínez 2,3\#, María García-Robles², Carolina Balmaceda-Aguilera², Ximena Koch², \\ Federico Rodríguez ${ }^{2}$, Carmen Silva-Álvarez ${ }^{2}$, Katterine Salazar², Viviana Ulloa², Francisco Nualart ${ }^{2,3 *}$ \\ 1 Faculty of Medicine, Concepcion University, Traumatológico Hospital, Concepción, Chile \\ 2 Laboratory of Neurobiology and Stem Cells, Department of Cellular Biology, Center for Advanced Microscopy CMA BIOBIO, University of Concepcion, Concepcion, Chile \\ 3 Laboratory for Stem Cell Transplantation CellT, Concepcion University, Concepción, Chile
}

\begin{abstract}
Cartilage has poor regeneration capacity due to the scarcity of endogenous stem cells, its low metabolic activity and the avascular environment. Repair strategies vary widely, including microfracture, autologous or allogenic tissue implantation, and in vitro engineered tissues of autologous origin. However, unlike the advances that have been made over more than two decades with more complex organs, including vascular, cardiac or bone tissues, similar advances in tissue engineering for cartilage repair are lacking. Although the inherent characteristics of cartilage tissue, such as the lack of vascularity and low cellular diversity, suggest that it would be one of the more simple tissues to be engineered, its functional weight-bearing role and implant viability and adaptation make this type of repair more complex. Over the last decade several therapeutic approaches and innovative techniques show promise for lasting and functional regeneration of hyaline cartilage. Here we will analyze the main strategies for cartilage regeneration and discuss our experience.
\end{abstract}

Key words: Cartilage; lesion; microfracture; stem cells

\section{INTRODUCTION}

Traumatic and chronic focal injuries to articular cartilage are frequent, especially among young athletes; the incidence of chondral lesions in arthroscopies ranges from 60\% to 66\% (Aroen et al., 2004; Curl et al., 1997; Widuchowski et al., 2007). Symptoms associated with these lesions include pain, stiffness, swelling and a clicking sound, among others, which can affect patients' work, physical activity and activities of daily living. Although the etiology is not well understood, they have the potential to progress to osteoarthritis (OA) of the joint along with all of the associated social and personal costs if left untreated.

Highly organized articular cartilage (Figure 1) is avascular, aneural and has little regeneration potential upon damage, which results in functional loss. Currently there are two major treatments for focal defects of the knee joint. The first approach involves stimulation of the bone marrow by inducing perforations (microfracture) or abrasions of the subchondral plate with the aim of generating scar tissue, which induces deposition of fibrocartilage derived from mesenchymal stem cells (MSCs) that is mechanically different from the hyaline cartilage (Steadman et al., 2003b). The second approach involves generation or transplantation of tissue with similar features, such as native hyaline cartilage. In this approach, autogenic and allogenic mature cartilage blocks or autogenous and allogenous chondrocytes are transplanted with the goal of generating hyaline-like tissue (Hangody et al., 1997).

Brittberg et al. (1994) initially reported the "first generation" of autologous chondrocyte implantation (ACI) in which a solution of in vitro cultured and expanded autologous chondrocytes were injected over the lesion under the periosteal flap. In the last 10 years this technique has been improved, using scaffolds as carriers for cells, in vitro cartilage-tissue constructions and using MSCs as a source to generate hyaline cartilage (Russlies et al., 2002; Trattnig et al., 2005). In addition, long-term follow-up studies reporting the outcomes of knee chondral lesions treated with the primary $\mathrm{ACI}$ and more recent techniques to transplant cells have been published, with adequate results (Beris et al., 2012; Filardo et al., 2012a; Pelissier et al., 2013; Rogers et al., 2010). However, questions regarding the structural quality of the repaired tissue, complications (e.g., graft hypertrophy) and the high cost of the procedure has motivated further research in this area (Brittberg, 2010).

We will review the techniques used to treat articular cartilage defects of the knee, as well as the indications and associated complications of these approaches. In addition, we will review the mid- to long-term follow-up clinical studies, with a focus on the cell-based therapies.

\section{REPAIR TECHNIQUES}

The most common surgical option to treat focal defects of knee cartilage includes bone marrow stimulation techniques that perforate the subchondral plate, creating small fractures with the aim of stimulating MSCs to generate a scar over the lesion. Among its advantages, bone marrow stimulation is a lowcost and relatively simple procedure (Steadman et al., 2003a; Steadman et al., 2003b). Current indications for microfracture are small full-thickness chondral defects (up to $4 \mathrm{~cm}^{2}$ ) in a stable, aligned knee.

The outcomes of microfracture are correlated with different factors, including size of the defect and patient characteristics. For example, traumatic lesions, lesions smaller than $4 \mathrm{~cm}^{2}$ and those with shorter onset of symptoms at the time of treatment 56-41-2204531; Fax: 56-41-2245975; Email: frnualart@udec.c 


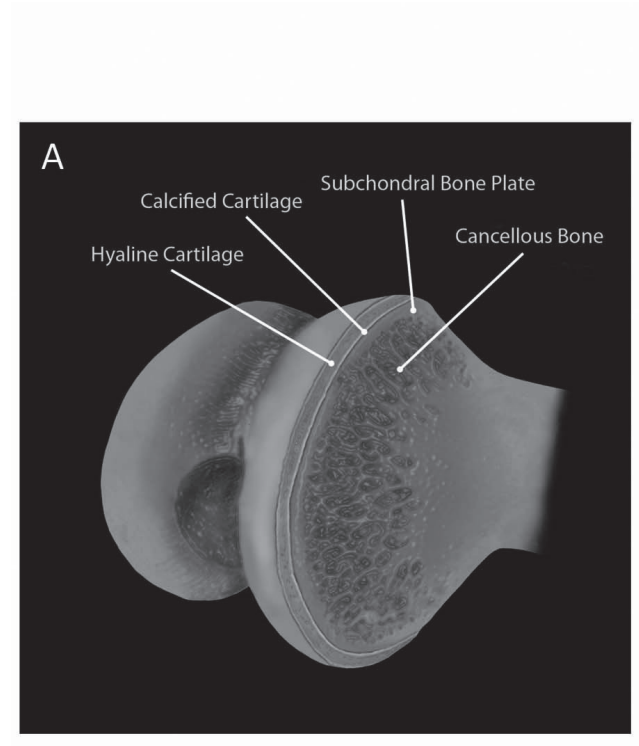

Hematoxylin \& eosin

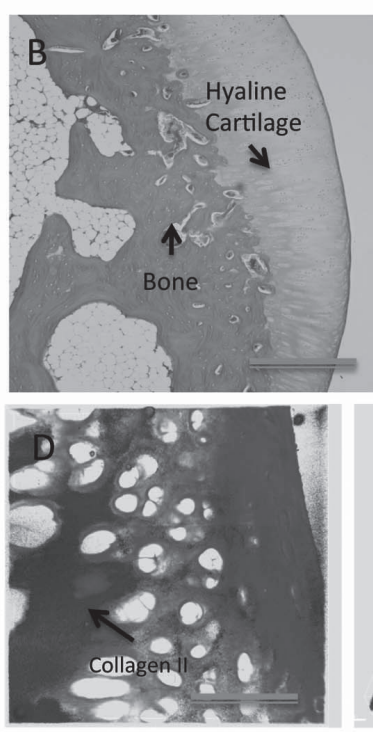

Two-photon confocal microscopy and 3D projection

Two-photon confocal microscopy

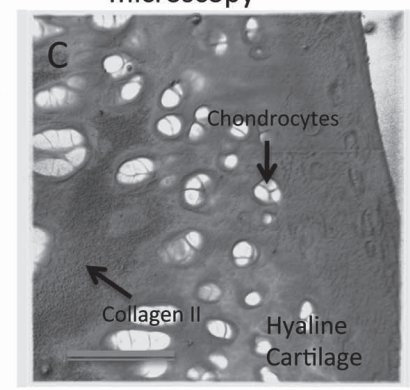

$E$

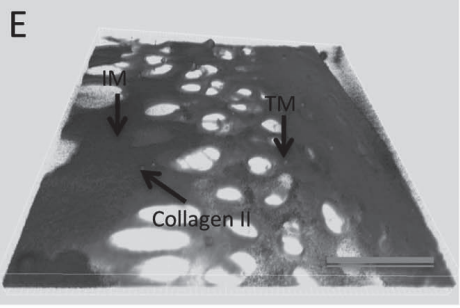

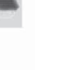

Figure 1. Normal histology of hyaline cartilage using two-photon microscopy.

A. Schematic representation of hyaline cartilage of the knee. B. Hyaline cartilage observed with hematoxylin and eosin staining. A homogenous surface was observed over the articular bone. C. Hyaline cartilage analyzed using two-photon confocal microscopy, showing chondrocytes and the cartilage matrix. D, E. Hyaline cartilage analyzed using two-photon confocal microscopy and 3D projection. Second harmonic generation showing type II collagen in red and the cartilage matrix in green. Several lacunae are visible. The territorial matrix (TM) and interterritorial matrix (IM) may also be discerned. Scale bars in B, $500 \mathrm{~mm}$; in C-E, $30 \mu \mathrm{m}$.

respond better to microfracture (Steadman et al., 2003a; Steadman et al., 2003b). In addition, females, older patients and patients with greater body mass index present with poorer outcomes (Mithoefer et al., 2005; Steadman et al., 2003a; Steadman et al., 2003b).

In an 11 year follow-up study of the outcomes of microfracture for traumatic full-thickness chondral defects in 71 knees, Steadman et al. (2003a) reported good and excellent clinical outcomes as measured with the Lysholm and Tegner scores. In a prospective follow-up study that included 48 patients with isolated full-thickness chondral defects of the condyles in stable knees, Mithoefer et al. (2005) found significant improvement in functional and subjective scores after a minimum follow-up of 2 years. The best results were observed in patients with better fill of the lesion as evaluated with magnetic resonance imaging (MRI), lower body mass index and shorter onset of symptoms (Mithoefer et al., 2005). In a recent retrospective case series study that evaluated 145 patients with a single chondral lesion of the knee joint, Salzmann et al. (2013) reported improvements in the clinical outcomes (International Knee Documentation Committee [IKDC], Lysholm and Tegner scores and the numeric analogue scale) following single lesion microfracture after a minimum follow-up of 2 years. Significantly better outcomes were observed in male patients and in those patients with a shorter duration of symptoms. Thus although satisfactory outcomes for microfracture have been reported for this cost-effective and relatively simple procedure, full recovery is not acheived in all patients (Salzmann et al., 2013). Moreover, the achieved clinical and structural outcomes may decrease over time (Kon et al., 2012).
2.1. Experimental approach to evaluate microfracture for knee cartilage repair

Hyaline cartilage is the most common and widely distributed type of cartilage; it is found in the tracheal rings, articular surfaces of synovial joints and developing bones in endochondral ossification. With the exception of articular cartilage, hyaline cartilage is enclosed by a perichondrium. The territorial matrix, which surrounds chondrocytes or chondrocyte clusters, is an intensely staining, basophilic matrix. The staining reaction is likely due to a higher concentration of stainable sulfated glycosaminoglycans or other ground substance macromolecules near the chondrocytes. In our analysis, the territorial matrix was Bismarck brown-positive and showed very low immunoreaction for type II collagen (Figure 2A-C). In contrast, most type II collagen immunoreaction was detected in the interterritorial matrix, which is relatively distant from the chondrocytes (Figure 2A), and collagen fibrils in the interterritorial matrix were larger than those fibrils closer to the chondrocytes. However, this matrix is less intensely stained using histochemical techniques (Figure 2B).

Knee arthrotomy and microfracture require drilling into the subchondral bone to release bone marrow that forms a stem cell-rich clot at the site of the wound, which spontaneously differentiates into fibrocartilage. We have analyzed knee lesions treated with microfracture in rabbits to evaluate the scar formed after treatment (Figure 4). The histochemical techniques of safranin, Bismarck brown and alcian blue staining were used to evaluate the lesion (Figure 4A-F). Additionally, immunohistochemical analysis for types 

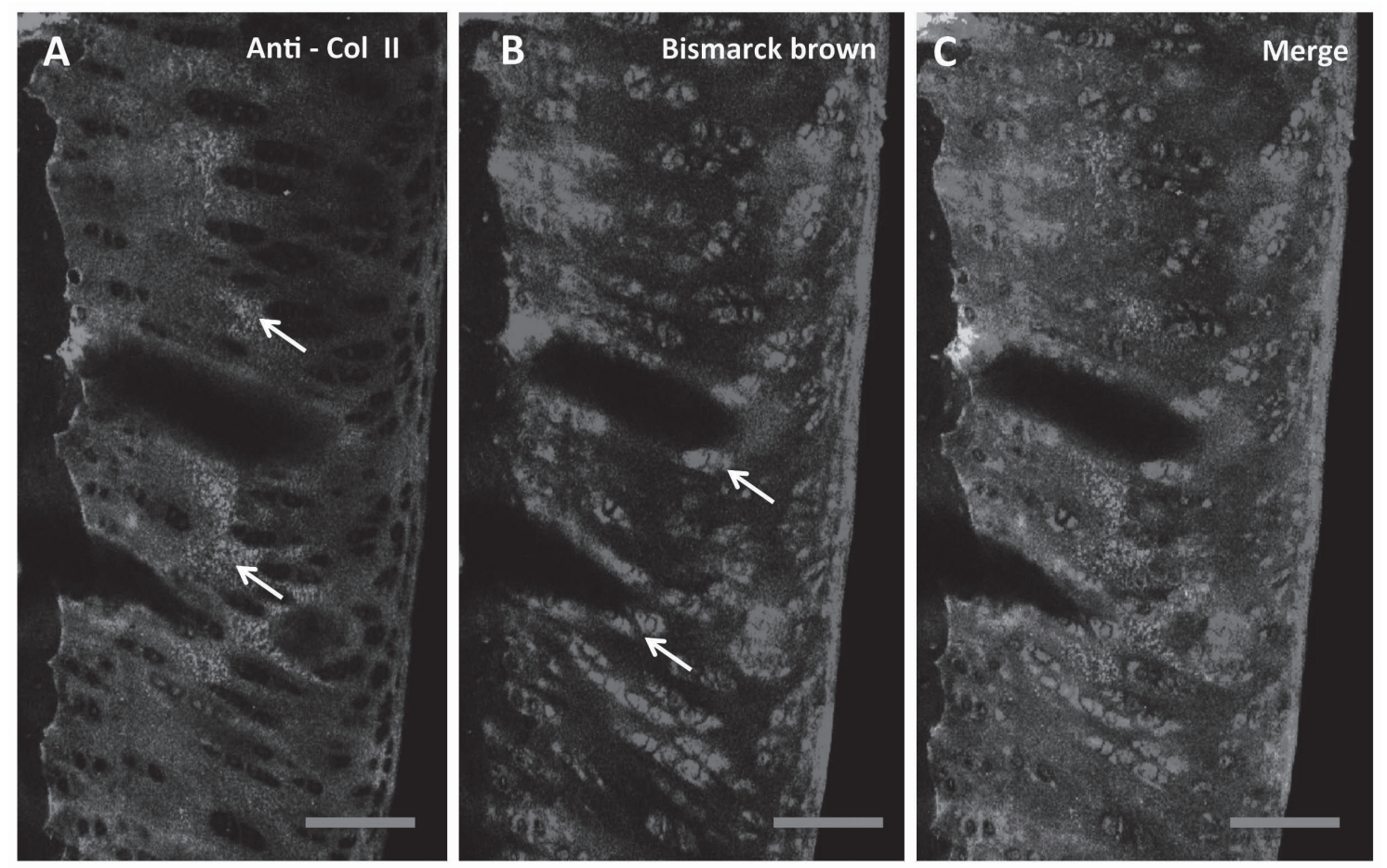

Figure 2. Histochemical and immunohistochemical analysis of cartilage.

A-C. Confocal microscopy analysis of different hyaline cartilage components after immunohistochemistry and fluorescence analysis for type II collagen (cy2 in green, $488 \mathrm{~nm}$ laser excitation) (A) and histochemical and auto-fluorescence detection after Bismarck brown staining (633 nm laser excitation) (B). A, B. Similar to the imaging generated with two-photon and second harmonic generation, type II collagen distribution is mainly observed in the inner part of the hyaline cartilage, forming the interterritorial matrix ( $A$, arrows). Bismarck brown staining is observed mainly in the territorial matrix (B, arrows). C. A low co-localization is observed between the stains. Scale bars in A-C, $50 \mu \mathrm{m}$.

I and II collagen and aggrecan was performed (Figure 4G-L). After microfracture, the scar tissue was negative for safranin and Bismarck brown staining and positive for type I collagen (Figure 3 and Figure 4B, D and H). The scar tissue was also negative for type II collagen and aggrecan (Figure 4J, L).

As described in previous reports, the experiments performed in this study allow us to conclude that the microfracture procedures are adequate to induce repair of the damaged articular cartilage. However, the neo-synthesized tissue in the lesions does not correspond to articular cartilage, which is mainly composed of type II collagen. The fundamental findings in the damaged tissue were the increased cellular proliferation and the deposition of type I collagen as identified with a collagen I-specific antibody. The cells formed a compact tissue with no apparent formation of territorial/inter-territorial matrices or isogenous groups. Furthermore, there was no deposition of other cartilage extracellular matrix components, including glycosaminoglycans, as was shown by the lack of safranin, Bismarck brown and alcian blue staining. Moreover, the neo-synthesized tissue did not show a positive reaction with an anti-aggrecan antibody. Thus the methods used for cartilage repair will have to incorporate new strategies to stimulate the synthesis of an articular matrix similar to that found in normal tissue.

\subsection{Osteochondral autograft and allograft transplantation}

In 1997, Hangody et al. (1997) first described mosaicplasty, in which autologous osteochondral plugs were harvested from a non-weight bearing area to treat osteochondral lesions of the knee joint in humans. Osteochondral cylinders were harvested using a tubular chisel, mostly from the superolateral side of the femoral trochlea to fill osteochondral lesions of weight-bearing areas of the same knee. Usually multiple cylinders are required to fill the lesion completely and to establish a congruent hyaline surface. Correct placement of the graft is crucial in order to prevent extensive pressure to the graft and avoid chondrocyte death; therefore grafts should be placed at the same level as the surrounding healthy cartilage, or slightly impacted (Duchow et al., 2000; Hangody et al., 2004; Whiteside et al., 2005).

This one-step procedure corrects the lesion with native hyaline cartilage from the same patient. Indications for this technique include Outerbridge grade III and IV cartilage loss and full-thickness chondral defects located in weight-bearing areas of the knee condyles and in the patellofemoral joint. The size of the defect is limited to $4 \mathrm{~cm}^{2}$ due to limitations in the donor area. As older patients present limited repair capacity, this procedure is indicated in patients younger than 45-50 years. If malalignment, meniscal and/or ligament lesions are present, these concomitant lesions should be addressed in order to permit adequate repair of the damaged cartilage. For larger lesions, the transference of an osteochondral allograft is an option; however, the lack of donors, difficulties in managing fresh allografts and the possibility of disease transmission make this a less suitable alternative (Bugbee et al., 2012; Demange and Gomoll, 2012; Gross et al., 2005).

Long-term outcomes of mosaicplasty were reported by Hangody et al. (2008). Of a total of 1097 mosaicplasties, 


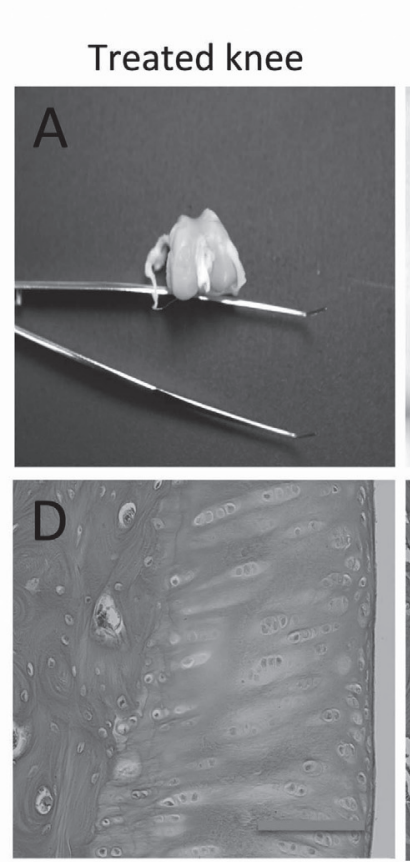

untreated control
Microfracture treated lesion
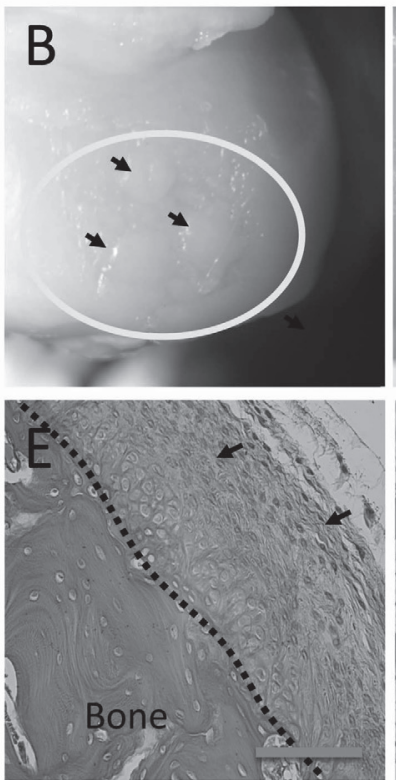

Microfracture

treated lesion

\section{Microfracture not treated lesion}
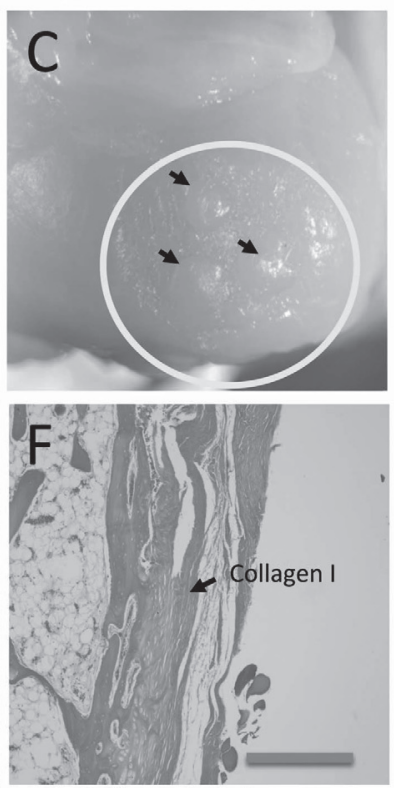

Microfracture

not treated lesion

Figure 3. Hyaline cartilage repair of knee arthrotomy using microfracture.

After induction of knee arthrotomy in rabbits, microfracture repair technique was undertaken in left knees; untreated right knees were used as controls. A. After microfracture, the knee appeared normal. B, C. Regenerated tissue was observed around the treated and untreated lesions (arrows). Histological analysis using hematoxylin and eosin staining showed different type of tissues in the lesion areas. D. Normal hyaline cartilage. E. Microfracture-treated lesion in which the scar is composed mostly of type I collagen and fibroblasts (arrows). F. The scar of the untreated lesion is composed mostly of type I collagen (arrows). Scale bars in D-F, $150 \mu \mathrm{m}$.

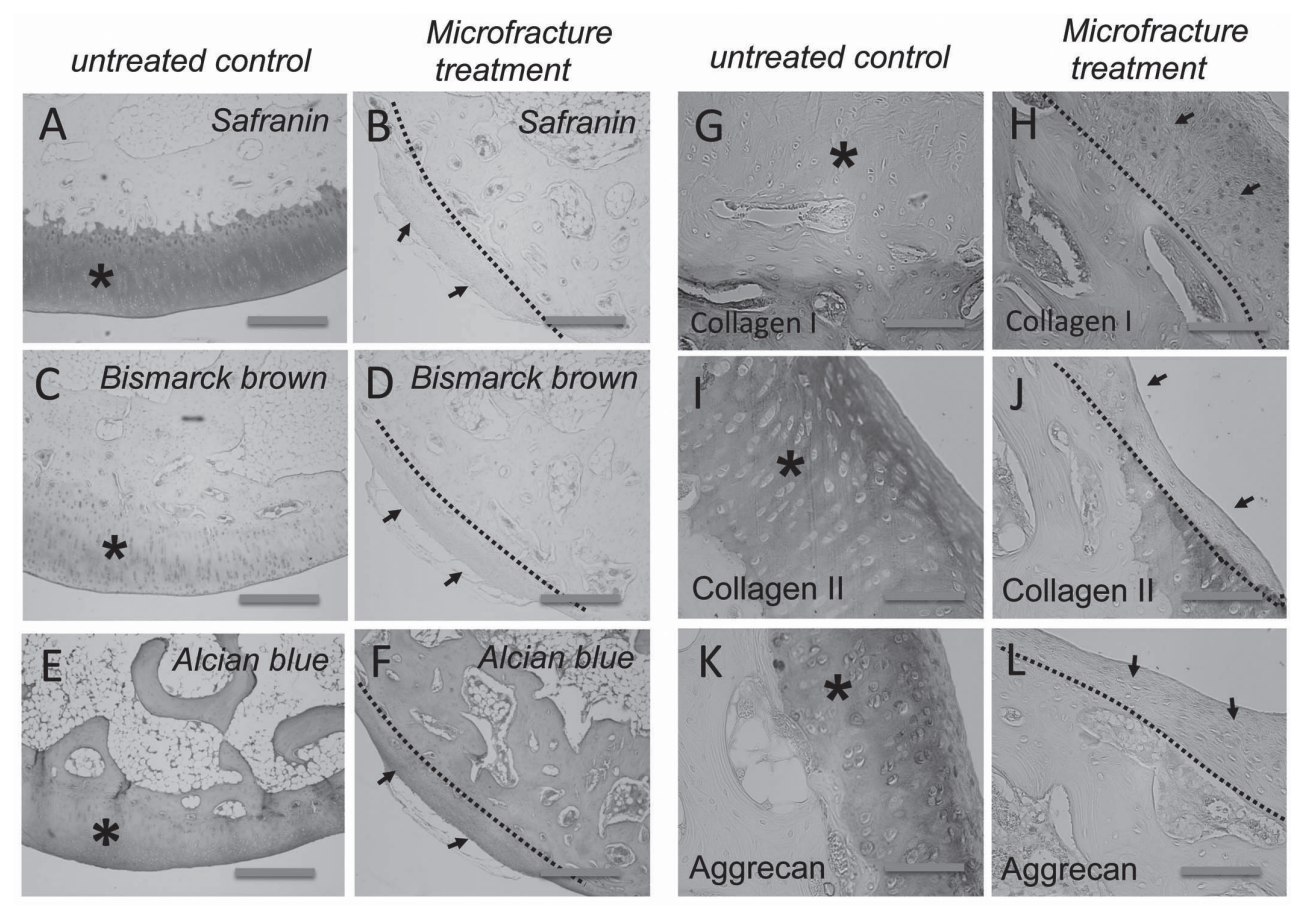

Figure 4. Immunohistochemical analysis of hyaline cartilage repair after knee arthrotomy and microfracture.

Knee arthrotomy and microfracture repair was undertaken in rabbits. A-F. After microfracture or not treated lesion, the scar was negative for safranin (B) and Bismarck brown (D) staining. Low reaction was observed with alcian blue staining (E-F). G, H. Anti-collagen type I immunoreaction was detected after microfracture. I-L. A negative immunoreaction was observed for anti-type II collagen and aggrecan (J and L). Asterisks, normal cartilage. Arrows, Treated lesion and scar. Scale bars in A-L, $100 \mu \mathrm{m}$. 
789 were in femoral condyles, 147 in the patellofemoral joint and 31 in tibial condyles. Concomitant reconstructive procedures, including anterior cruciate ligament (ACL) reconstructions, realignment osteotomies, meniscus surgeries and patellofemoral realignment procedures were performed. At last follow-up, good or excellent results were encountered in $92 \%$ of patients with femoral condyles defects, $87 \%$ with tibial defects and $74 \%$ of patients with patellar or trochlear defects. In a recent long-term follow-up analysis of 73 patients (mean age of 34 years) with focal full-thickness chondral lesions of the knee, Solheim et al. (2013) reported significant improvement in mean Lysholm score and visual analogue scale for pain after 10-14 years of follow-up. However, up to $40 \%$ of the patients had a poor Lysholm score ( $<64$ points); poorer scores were observed in older patients ( $>40$ years), women, and in those with defects larger than $3 \mathrm{~cm}^{2}$ (Solheim et al., 2013).

Reported limitations of mosaicplasty include morbidity in the donor area, lesion size limitation $\left(<4 \mathrm{~cm}^{2}\right)$, and the eventual mortality of the chondrocytes from the cylinder edges, which can be associated with poor incorporation of the plug into the surrounding healthy cartilage.

\subsection{Autologous chondrocyte transplantation}

In 1994, Brittberg et al. reported the results of a novel technique used to treat full-thickness cartilage defects of the knee, in which they arthroscopically harvested a sample of healthy hyaline cartilage from the damaged knee. Chondrocytes were subsequently isolated, cultured and expanded for 14 to 21 days, after which a solution of the cultured cells was injected over the damaged area, which was covered previously with a flap of periosteum. After 2 years of follow-up, 14 of 16 patients with condylar lesions and 2 of 7 patients with patellar transplants presented with good to excellent outcomes. Biopsies of 11 femoral transplants and one patellar transplant revealed the appearance of hyaline cartilage (Brittberg et al., 1994).

Advantages of this procedure include the capacity to treat lesions greater than $4 \mathrm{~cm}^{2}$ and the eventual repair of the lesion with hyaline cartilage. In addition, this procedure does not require the harvesting of osteochondral plugs from donor areas of the knee. Current indications for this procedure are chronic and traumatic full-thickness chondral lesions of the knee in patients younger than 50 years and those with failed repairs using other techniques, including microfracturing and mosaicplasty. As with the other techniques, a higher bodymass index, older age at the time of surgery and the duration of the symptoms correlated with poorer outcomes (Jaiswal et al., 2012).

Some problems associated with this first generation technique included the eventual in vitro dedifferentiation of the chondrocytes into fibroblast-like cells in response to monolayer culturing, as well as graft hypertrophy, difficulties suturing the periosteal flap and the resultant leakage of the cells and non-homogenous accumulation of the suspended cells. As a result, subsequent studies developed different scaffolds composed of animal types I and III collagen, polyglycolic/polylactic acid, hyaluronic acid, fibrin gel and alginate to secure the cells within the lesion (i.e., matrix-assisted ACI, MACI; matrix-associated chondrocyte transplantation, MACT; and matrix-based ACI), as well as construction of engineered cartilage to achieve a more uniform repair of the lesion (Behrens et al., 2006; Beris et al., 2012; Filardo et al., 2012b; Pelissier et al., 2013; Rogers et al., 2010). The parameters and outcomes of mid- and long-term studies of patients treated with ACI, ACI seeded in scaffolds and other tissue-engineered cartilage techniques are listed in Table 1.

Postoperative evaluation of patients receiving matrixinduced procedures using MRI have shown adequate quality of the tissue, with almost complete filling of the lesion, restoration of the articular surface and integration of the tissue (Cherubino et al., 2003; Trattnig et al., 2005). Second-look arthroscopies have shown incorporation of the graft into the knee and a macroscopic appearance similar to the surrounding healthy cartilage. At short- to mid-term follow-up, histological evaluation of the repaired tissue showed good integration and characteristics of hyaline-like cartilage, including columnar distribution of the cells and the presence of hyaline-like cartilage extracellular matrix (ECM) consisting of type II collagen, proteoglycans, chondroitin sulfate and S-100 protein (Bartlett et al., 2005; D'Anchise et al., 2005; Zheng et al., 2007).

Despite the adequate clinical outcomes reported for ACI and its subsequent derivative procedures, the structural properties of native hyaline cartilage have still not been achieved. The reported problems and complications, including the in vitro dedifferentiation of mature chondrocytes, the presence of graft hypertrophy even in matrix-induced procedures, lack of incorporation, loss of the implant and the requirement for a previous arthroscopy to obtain a biopsy of healthy chondrocytes, have motivated further research to investigate the therapeutic potential of other scaffolds and cellular sources such as heterologous chondrocytes and MSCs (Hwang et al., 2009; Kon et al., 2012; Niethammer et al., 2013).

\section{STEM CELL THERAPY}

Given the difficulty in isolating endogenous cartilage stem cells, studies have focused on identifying a cell type that is easily and rapidly expandable and capable of differentiating into chondrocytes. Recently, MSCs have received much attention due to their multipotency, wide histological distribution and capability to differentiate into cells of the chondrocyte lineage (Gardner et al., 2013). For example, bone marrow-derived and umbilical cord MSCs (BM-MSCs and UC-MSCs, respectively) have been widely used in vitro to recreate hyaline cartilage; however, generation of longstanding implants that meet the mechanical and functional cues necessary has yet to be shown (Wang et al., 2009). Therefore, current strategies aim to improve graft integration and the differentiation of the expanded cells towards a true chondrocyte lineage, which should secrete the proper ECM molecules, including types II, X and XI collagen, aggrecan, SOX9 and lubricin, that give cartilage its fundamental mechanical characteristics.

Adding different organic scaffolds to concentrate and stimulate stem cell differentiation can augment the microfracture procedure or promote the in vitro or in situ differentiation of BMSC-engineered tissue, thereby improving hyaline quality and increasing fill percentage (Gomoll, 2012; Siclari et al., 2012). However, although many scaffold strategies have good in vitro or in vivo outcomes in animal models, their use for cartilage repair in humans has been discouraged 


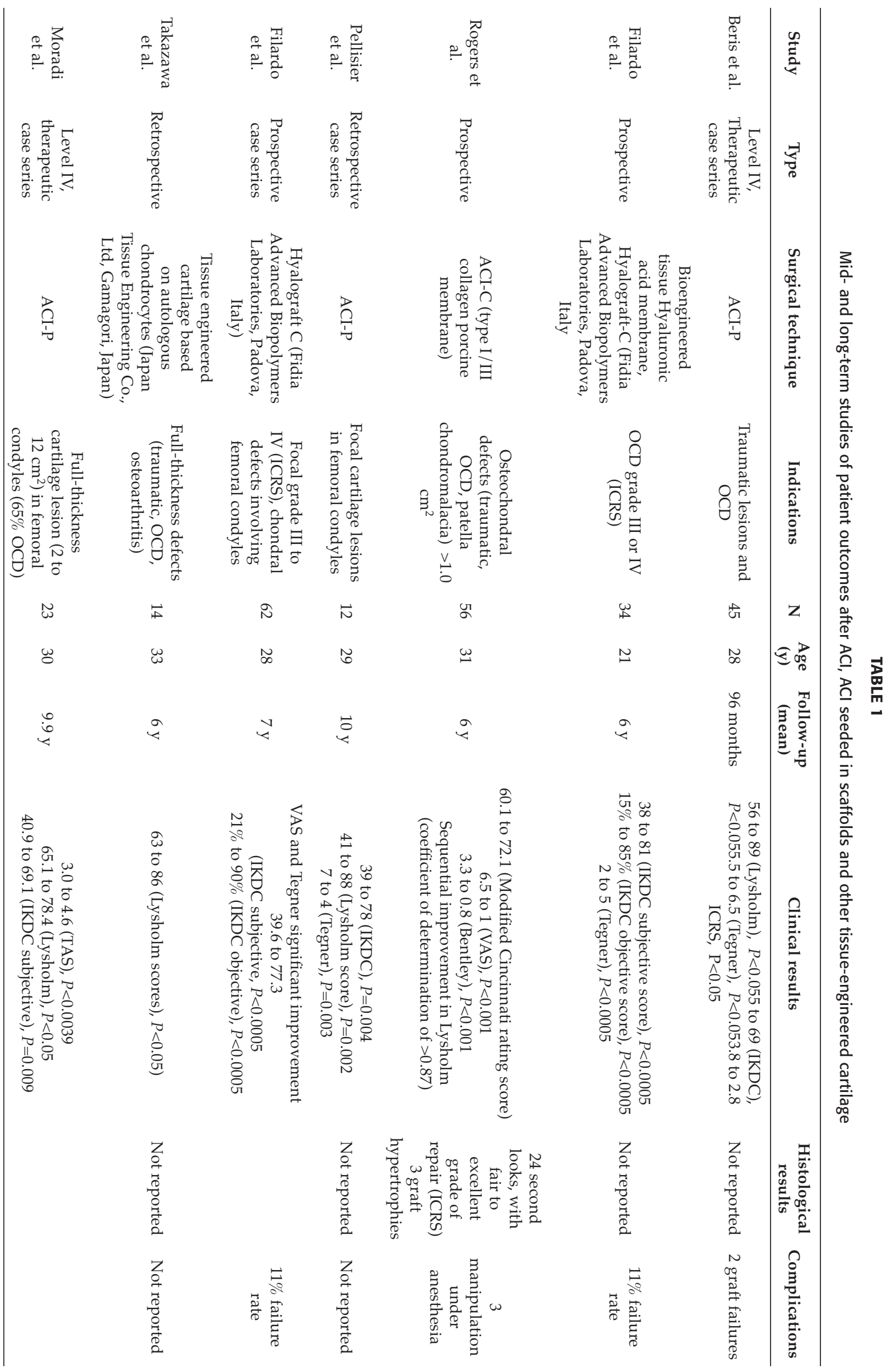


because of several safety concerns regarding possible side effects (van der Kraan et al., 2002).

Another line of investigation with successful preclinical development explores the implantation of scaffoldless engineered cartilage, exploiting the self-organization and selfassembling characteristics of cells cultured in non-adherent conditions. This technique involves the generation of small spherical aggregates of cartilage from a critical mass of cells. In the absence of adhesive substrates these aggregates self-assemble, develop rounded cell morphology typical of chondrogenic phenotype and form spheres reminiscent of native cartilage formation (Handschel et al., 2007). This alternative has several advantages over the use of scaffolds; it avoids the unsynchronized degradation of ECM in neotissue formation that is important for remodeling and integration as well as critical for its functional properties. Additionally, it avoids scaffold-induced toxicity and immunogenicity (Liu and $\mathrm{Ma}, 2004$ ), phenotype alteration (Levy-Mishali et al., 2009) and pressure-tension force-induced differentiation (Bryant et al., 2004). Studies using this strategy report tissues with higher ECM content and mechanical properties (Aufderheide and Athanasiou, 2007; Dehne et al., 2009). Additionally, type VI collagen generation in the perichondrial matrix (PCM), a functional structure important for the development of cartilage characteristics, has been shown, along with the secretion of types II and VI collagen and GAG (CS-4, CS-6) that induce native cartilage development (Ofek et al., 2008). In general terms, this technique better represents the sequential phases of development seen in native cartilage formation $(\mathrm{Hu}$ and Athanasiou, 2006; Ofek et al., 2008) and overcomes the clinical concerns regarding the use of scaffolds. On the other hand, certain drawbacks remain. For example, reported studies have mainly relied on animal non-expanded autologous chondrocytes to avoid dedifferentiation (Ofek et al., 2008). However, it is not possible to harvest similar quantities of human chondrocytes.

The main challenge today is the correct differentiation of highly expandable cells, such as MSCs and induced pluripotent stem cells (iPSCs). As the latter is still in its infancy, most studies have analyzed BMSCs. BMSCs have recently been used as a viable cellular substrate in combination with the micromass technique. This technique involves the reaggregation of a critical mass of initially dispersed BMSCs into small spheres, which grow in a three-dimensionaal (3D) suspension culture for several weeks. The neocartilage formed this way can then be transplanted alone into the injured site to complete differentiation or in combination with microfracture or the other aforementioned techniques. Furthermore, this method is very useful to assess the effect of different molecules on the cartilage differentiation process. However, the hurdles of this approach include the generation of tissues with multiple cellular phenotypes and a much wider genotypic background, such as fibrochondrocytes and hypertrophic chondrocytes that secrete molecules which are not typically found in native cartilage (Johnstone et al., 1998; Sekiya et al., 2005). For example, these cells express not only hyaline cartilage, but also the hypertrophy markers (e.g., type $\mathrm{X}$ collagen and matrix metalloproteinase 13 [MMP13]) and bone markers (e.g., type I collagen, osteopontin and bone sialoprotein) (Pelttari et al., 2008; Steck et al., 2005). Therefore, they generate an ECM that does not fulfill the mechanical properties compatible with physical integration. Thus obtaining a cell-homogeneous tissue seems to be one of the critical points for implant viability.

Cartilage spheres can be generated using a self-assembling process, pellet culture or aggregate culture. The basic protocol to obtain cartilage using the pellet protocol involves BMMSCs placed in conical propylene tubes and then cultured in serum-free chondrogenic medium, typically containing DMEM supplemented with proline, pyruvate, ITS (insulin, transferrin and selenium), bovine serum albumin (BSA), linoleic acid and 2-phosphate ascorbic acid (AA-2P). Currently, researchers use agarose, 2-hydroxyethyl methacrylate (Novotny et al., 2006) or semi-permeable membranes (Brehm et al., 2006) as nonadherent substrates to coat culture wells.

Similar approaches have been used with human UC-MSCs (Liu et al., 2013; Pelttari et al., 2008). Compared to human BMSCs, human UC-MSCs have the advantages of abundant supply, painless collection and faster and longer self-renewal in vitro. Recently, Wang et al. (2009) demonstrated that hUCMSCs produce more glycosaminoglycans and collagen than hBM-MSC. Similarly, they produce types I and II collagen and aggrecan, suggesting that hUC-MSCs are the optimal cells for fibrocartilage tissue engineering.

Several molecules that regulate cellular differentiation have been used in the generation of cartilage spheres, and several signaling pathways are known to induce the chondrogenic phenotype. For example, studies have reported that this differentiation protocol can be enhanced by adding tumor growth factor (TGF)- $B 3,10^{7} \mathrm{M}$ dexamethasone (DEX), and bone morphogenic proteins (BMPs) (Johnstone and Yoo, 2001; Sekiya et al., 2005). Microarray analysis of approximately 12000 genes in BMSCs has shown that TGF-B3 and DEX in combination with BMP-4, BMP-6, and especially BMP-2 increase the cartilage weight and the expression of the critical genes for cartilage synthesis in the expected time sequence (Sekiya et al., 2005). These included cartilage-specific genes such as types II, IX, and XI collagen, chondroadherin, aggrecan and SOX-9. Moreover, the SOX-9 transcription factor has been described as promoting the expression of types II, IX, and XI collagen as well as aggrecan (Lefebvre et al., 2001). However, in this report, upregulation of non-specific genes, including hypertrophic chondrocyte markers (e.g., type X collagen, parathyroid hormone-related protein receptor [PTHrP-R], integrin-binding sialoprotein [IBSP] and osteomodulin) raise the possibility that the implanted cells become calcifying after in vivo implantation, indicating that this protocol needs perfection. In addition, Weiss and colleagues (2010) have described protocols in which acidic fibroblast growth factor (aFGF/FGF1) and insulin growth factor (IGF)-1 exert an inducing capacity that was similar to the aforementioned molecules. Additionally, they reported PTHrP and bFGF as early and late inhibitors of chondrogenesis necessary for inhibition of chondrocyte hypertrophy in vitro. However, they were not able to inhibit type $\mathrm{X}$ collagen expression or in vivo calcification, indicating that terminal chondrocyte differentiation was not achieved as the inhibiting molecules were not produced by the implanted cells (Zhang et al., 2012).

Recently, new molecules that regulate chondrocyte differentiation, including kartogenin (KGN) (Johnson et al., 2012), chondroitinase-ABC (C-ABC) and TGF- $\beta 1$ (Responte et al., 2012), have been explored. Specifically, KGN was used in a chondrogenic model using human BMSCs, achieving promotion of chondrocyte differentiation (median effective 
concentration $=100 \mathrm{nM}$ ) and chondroprotective effects in vitro; it was also shown to be efficacious in alleviating the symptoms of two OA animal models. Most interestingly, KGN binds filamin A, disrupting its interaction with the transcription factor, core-binding factor $\mathrm{b}$ subunit $(\mathrm{CBFb})$ and induces chondrogenesis by regulating the CBFb-RUNX1 transcriptional program. In this respect, the interplay between RUNX1, RUNX2 and RUNX3 modulates the differentiation of chondrocytes, where RUNX1 is important for the initial growing and secreting phase, and RUNX2 and 3 predominate in the final differentiation phase. On the other hand, Responte et al. (2012) used immature bovine chondrocytes to develop a novel self-assembly process for articular chondrocytes, which was improved using a combination of catabolic and anabolic agents. Specifically, TGF- $\beta 1$ in conjunction with C-ABC additively increased the tensile properties and synergistically enhanced the collagen content; microarray analysis indicated that TGF- $\beta 1$ upregulated MAPK signaling while C-ABC increased collagen fibril diameter and density. At four weeks post-transplantation in nude mice, mature neocartilage expressing type II collagen and GAGs was observed.

\subsection{Engineering of heterologous MSCs into cartilage}

Although autologous transplantation using MSCs is currently the most commonly used cell for cartilage repair, the use of heterologous transplantation presents many advantages that cannot be matched by allogenic or autologous strategies, including the availability of a relatively abundant supply without the need for additional surgical interventions, as is the case for autologous transplantation. However, contagious diseases and a shorter life span of implanted animal cells are some of the concerns that discourage this option (Kaminski et al., 1980; Ksiazek and Moskalewski, 1983; Malejczyk et al., 1991; Revell and Athanasiou, 2009). Most of these problems can be overcome, as diseases can be limited by controlled breading, and implant viability of only a few years is currently acceptable. Finally, several mechanisms that promise to overcome immunogenicity towards the xeno-implanted cells have been reported.

Although intramuscular xenografts of rat chondrocytes into a rabbit host readily generated an important humoral immune response due to the high vascularity of the tissue (Osiecka-Iwan et al., 2003), different results have been reported when the xenografts were implanted into a cartilage defect inside the joint, which is considered an immuno-privileged environment as it is avascular (Bolano and Kopta, 1991). One study addressing this used pig chondrocytes implanted into human cartilage defects in vitro and showed an important degree of wound filling and the synthesis of important levels of collagen fibers (types I and II) and proteoglycans (Fuentes-Boquete et al., 2004). Furthermore, varying degrees of responses have been described in different experimental settings when the grafts are implanted in vivo into joint defects, which was dependant on how the heterologous cells were implanted. For example, after rabbit articular cartilage defects were treated with pig chondrocytes and covered with a periosteal graft, significant tissue repair was observed after 24 weeks, showing a 90\% defect fill and a good histological score; furthermore, neocartilage showed chondrocyte like cells, a smooth hyaline morphology and no tissue rejection was reported (Ramallal et al., 2004). In another report, rabbit chondrocytes suspended in fibrin glue were transplanted into goat full-thickness articularcartilage defects. Macroscopic, histological and biochemical determinations showed that the xenografts produced matrix inside the fibrin glue and that rejection of transplanted cells did not occur. However, although histological analysis initially indicated that the defects treated with xenografts had a better regeneration tendency, this advantage was lost by the conclusion of a 52-week follow-up (van Susante et al., 1999). Additionally, a method called decellularization by photo-oxidation, which increases collagen fiber crosslinks by immersing the xenograft in a $0.01 \%$ methylene blue solution under specific conditions, showed no immunogenicity towards osteochondral xenotransplants from cattle shoulder joints into femoral condyles of sheep (von Rechenberg et al., 2003). This approach also reduced the factors that impair implant viability, such as resorption of subchondral bone and cyst lesions, thereby improving graft stability and cartilage survival (von Rechenberg et al., 2003). As this procedure kills the cells and destroys the intracellular antigenic proteins and DNA while preserving a functional ECM, it is believed to provide a viable option for tissue replacement. The use of MSCs in xenogeneic transplantation represents a step further as they have been reported to be immunoprivileged and do not generate an immune response when exposed to different types of immune cells in vitro (Aggarwal and Pittenger, 2005). An alternative method embraced this concept for osteochondral defect repair using a bone anchor to settle and graft the neocartilage better (Jang et al., 2013). hMSCs that were induced to differentiate in vitro (D-MSC) in conjunction with a biphasic composite construct consisting of fibrin glue and hydroxyapatite were implanted into osteochondral defects of adult New Zealand white rabbits. After 8 weeks the cartilage implants showed excellent macroscopic evaluation with a hyaline-like appearance and good defect filling. Furthermore, RT-PCR analysis showed increased expression of ECM proteins compared to non-differentiated MSCs (U-MSC). Histological evaluation showed good levels of safranin $\mathrm{O}$ staining and type II collagen that had a similar staining pattern to its surrounding tissue. Most importantly, no inflammation or immune cell infiltration was observed, indicating that xenogeneic transplantation using differentiated MSCs and a biphasic scaffold that anchors the neocartilage to the bone effectively repaired osteochondral defects. Although encouraging strategies have been reported, most of these studies need longer evaluation periods to establish the longterm functional viability of the xenotransplants that could enable them to scale towards clinical trials.

\section{CONCLUSIONS}

Cartilage has an extremely reduced regenerating capacity; therefore, multiple experimental approaches have been used to treat lesions in this tissue. The microfracture technique has been widely used in the clinic; however, the formation of cartilaginous tissue is scarce, yielding mainly a fibrocartilage. The isolation and application of MSCs together with collagen matrices is currently generating more effective repair models. Thus it is important to unveil the factors that stimulate the formation of articular cartilage to allow the in vitro synthesis of three-dimensional constructs for implantation in patients with pathologies of the knee cartilage. Finally, it is also 
important to indicate that progress in intra-articular therapy is being achieved in new clinical trials using corticosteroid and hyaluronic acid preparations (Evans et al., 2013). The joint utilization of these trophic factors and stem cells will be the new challenge in the future treatment of arthropathies.

\section{MATERIAL AND METHODS}

Knee arthrotomy and microfracture. Ten three-month-old female California rabbits weighing $3 \mathrm{~kg}$ were used to evaluate the effects of microfracture on the recovery from arthrotomy. Briefly, animals were initially anesthetized with $1 \mathrm{mg} / \mathrm{kg}$ tramadol, $1 \mathrm{mg} / \mathrm{kg}$ ketoprophene and antibiotics; animals subsequently received a subcutaneous injection of a $0.2 \mathrm{~mL}$ a mix containing Xylacine $(8 \mathrm{mg} / \mathrm{kg})$, Pacifor $(1 \mathrm{mg} / \mathrm{kg})$ and Ketamine $(30 \mathrm{mg} / \mathrm{kg}$ ) to maintain anesthesia. A longitudinal incision over the knee was made to expose the articulation followed by medial patella dislocation. Full-thickness osteochondral lesions of $5 \mathrm{~mm}$ in diameter were induced in the medial load-bearing condyles of both knees. Microfracture was performed in the left knee lesions with $1.5 \mathrm{~mm}$ interspace; right knees were used as untreated controls. After the wounds were sealed and sterilized, recovery from the anesthesia was induced. The histological analysis was performed after three months.

Histologic evaluation of microfracture-treated and control animals. Samples were fixed in formalin for 1 week at room temperature, after which they were decalcified by incubating in $45 \%$ formic acid solution with $20 \%$ sodium citrate, which was changed every 2-3 days during 3 weeks as described by Ana Morse (Molina et al., 2001). After the area of interest was isolated and washed thoroughly in distilled water, it was dehydrated in ascending ethanol graded solutions and embedded in paraffin blocks.

Bismarck brown staining. Deparaffinized tissues were hydrated in descending ethanol solutions and incubated with $1 \%$ aqueous Bismarck brown solution for $5 \mathrm{~min}$. After the tissues were washed in $95 \%$ ethanol, they were incubated with $0.5 \%$ methyl green solution until the slides turned dark green. Slides were then dehydrated in ascending ethanol solutions and xylol and mounted with Entellan medium.

Alcian blue staining. For intense blue cartilage staining, deparaffinized tissues were hydrated to distilled water in descending ethanol solutions and incubated for $30 \mathrm{~min}$ in recently filtered $0.5 \%$ Alcian-blue $8 \mathrm{GX}$ solution $(\mathrm{pH} 2.5)$, prepared with $3 \%$ acetic acid. Slides were then briefly washed with distilled water and counterstained for 5 min with $0.1 \%$ Kernechkrot solution for nuclear staining. Slides were next rapidly washed in distilled water, dehydrated in ascending ethanol solutions and xylol and then mounted with Entellan medium.

Combined method for fast green and safranin staining. Tissues were deparaffinized and hydrated to distilled water in descending ethanol solutions and then incubated for $3 \mathrm{~min}$ in $0.01 \%$ Fast Green solution. Stained slides were then washed with $1 \%$ acetic acid and later stained for 5 min with $0.1 \%$ Safranin O solution. Slides were dehydrated in ascending ethanol solutions and xylol and then mounted with Entellan medium.
Immunohistohemical detection of extracellular molecules. Tissue sections of $7 \mu \mathrm{m}$ thickness were deparaffinized in xylol and $100 \%$ ethanol and permeabilized for $15 \mathrm{~min}$ with methanol, followed by hydration to distilled water in descending ethanol solutions. Endogenous peroxidase activity was inhibited by incubation in $10 \% \mathrm{H}_{2} \mathrm{O}_{2}$ for $15 \mathrm{~min}$, after which slides were washed three times for $10 \mathrm{~min}$ each in Tris-phosphate buffer (TPB) $(\mathrm{pH} \mathrm{7.8)}$ at room temperature and incubated for $18 \mathrm{~h}$ with primary antibodies in a humid chamber. The following primary antibodies were used: anticollagen type I (Sigma-Aldrich, Saint Louis, Missouri, USA); anti-collagen type II (Abcam, Cambridge, Massachusetts, USA); anti-aggrecan [or anti-cartilage proteoglycan] (MerkMillipore, Darmstadt, Hesse, Germany). After slides were washed three times in TBP for $10 \mathrm{~min}$ each, they were incubated for $2 \mathrm{~h}$ with peroxidase-conjugated secondary antibodies, washed three times in TBP for $10 \mathrm{~min}$ each and developed using diaminobenzidine (DAB) substrate; slides were then washed with running tap water and then with distilled water. Additionally, contrast staining was performed with hematoxylin to reveal nuclei.

Second harmonic and multiphoton microscopy. Transplanted knee-joints were excised, fixed in Bouin's solution and prepared histologically as previously described. The $7-\mu \mathrm{m}$ thick neocartilage sections were deparaffinized, hydrated to distilled water and then mounted with fluorescent mounting medium (DAKO). Collagen deposition was analyzed by second harmonic image generation. The images were acquired in a Zeiss 40X multiphoton microscope LSM 780-NLO. Both signals, two-photon fluorescence (TPF) and second harmonic generation (SHG), were produced by excitation with a MaiTai Ti:Sapphire laser at $940 \mathrm{~nm}$. We used a LP490/SP485 NDD filter for SHG, and a BP565-610 NDD filter for fluorescence. In each case, ten images were acquired serially $(512 \times 512 \mu \mathrm{m})$ in Z-stack and joined together to one merged image. The acquired images were then processed by Imaris software (Bitplane v.7.3) to yield 3D reconstruction projections.

\section{ACKNOWLEDGMENTS}

This study was funded by an Innova Bio-Bio grant (08-PC S1-468) to FN and Conicyt PIA ECM-12, CMA-Bio-Bio Center grant.

\section{REFERENCES}

AGGARWAL S, PITTENGER MF. (2005) Human mesenchymal stem cells modulate allogeneic immune cell responses. Blood 105:1815-1822.

AROEN A, LOKEN S, HEIR S, ALVIK E, EKELAND A, GRANLUND OG, ENGEBRETSEN L. (2004) Articular cartilage lesions in 993 consecutive knee arthroscopies. Am J Sports Med 32:211-215.

AUFDERHEIDE AC, ATHANASIOU KA. (2007) Assessment of a bovine coculture, scaffold-free method for growing meniscus-shaped constructs. Tissue Eng 13:2195-2205.

BARTLETT W, SKINNER JA, GOODING CR, CARRINGTON RW, FLANAGAN AM, BRIGGS TW, BENTLEY G. (2005) Autologous chondrocyte implantation versus matrix-induced autologous chondrocyte implantation for osteochondral defects of the knee: a prospective, randomised study. J Bone Joint Surg Br 87:640-645.

BEHRENS P, BITTER T, KURZ B, RUSSLIES M. (2006) Matrix-associated autologous chondrocyte transplantation/implantation (MACT/MACI)-5-year follow-up. Knee 13:194-202. 
BERIS AE, LYKISSAS MG, KOSTAS-AGNANTIS I, MANOUDIS GN. (2012) Treatment of full-thickness chondral defects of the knee with autologous chondrocyte implantation: a functional evaluation with long-term follow-up. Am J Sports Med 40:562-567.

BOLANO L, KOPTA JA. (1991) The immunology of bone and cartilage transplantation. Orthopedics 14:987-996.

BREHM W, AKLIN B, YAMASHITA T, RIESER F, TRUB T, JAKOB RP, MAINIL-VARLET P. (2006) Repair of superficial osteochondral defects with an autologous scaffold-free cartilage construct in a caprine model: implantation method and short-term results. Osteoarthritis Cartilage $14: 1214-1226$

BRITTBERG M. (2010) Cell carriers as the next generation of cell therapy for cartilage repair: a review of the matrix-induced autologous chondrocyte implantation procedure. Am J Sports Med 38:1259-1271.

BRITTBERG M, LINDAHL A, NILSSON A, OHLSSON C, ISAKSSON O, PETERSON L. (1994) Treatment of deep cartilage defects in the knee with autologous chondrocyte transplantation. N Engl J Med 331:889-895.

BRYANT SJ, ANSETH KS, LEE DA, BADER DL. (2004) Crosslinking density influences the morphology of chondrocytes photoencapsulated in PEG hydrogels during the application of compressive strain. J Orthop Res 22:1143-1149.

BUGBEE W, CAVALLO M, GIANNINI S. (2012) Osteochondral allograft transplantation in the knee. J Knee Surg 25:109-116.

CURL WW, KROME J, GORDON ES, RUSHING J, SMITH BP, POEHLING GG. (1997) Cartilage injuries: a review of 31,516 knee arthroscopies. Arthroscopy 13:456-460.

CHERUBINO P, GRASSI FA, BULGHERONI P, RONGA M. (2003) Autologous chondrocyte implantation using a bilayer collagen membrane: a preliminary report. J Orthop Surg (Hong Kong) 11:10-15.

D'ANCHISE R, MANTA N, PROSPERO E, BEVILACQUA C, GIGANTE A. (2005) Autologous implantation of chondrocytes on a solid collagen scaffold: clinical and histological outcomes after two years of follow-up. J Orthopaed Traumatol 6:36-43.

DEHNE T, KARLSSON C, RINGE J, SITTINGER M, LINDAHL A. (2009) Chondrogenic differentiation potential of osteoarthritic chondrocytes and their possible use in matrix-associated autologous chondrocyte transplantation. Arthritis Res Ther 11:R133.

DEMANGE M, GOMOLL AH. (2012) The use of osteochondral allografts in the management of cartilage defects. Curr Rev Musculoskelet Med 5:229-235.

DUCHOW J, HESS T, KOHN D. (2000) Primary stability of press-fitimplanted osteochondral grafts. Influence of graft size, repeated insertion, and harvesting technique. Am J Sports Med 28:24-27.

EVANS CH, KRAUS VB, SETTON LA. (2013) Progress in intra-articular therapy. Nat Rev Rheumatol. 5:1-12.

FILARDO G, KON E, BERRUTO M, DI MARTINO A, PATELLA S, MARCHEGGIANI MUCCIOLI GM, ZAFFAGNINI S, MARCACCI M. (2012a) Arthroscopic second generation autologous chondrocytes implantation associated with bone grafting for the treatment of knee osteochondritis dissecans: Results at 6 years. Knee 19:658-663.

FILARDO G, KON E, DI MARTINO A, PATELLA S, ALTADONNA G, BALBONI F, BRAGONZONI L, VISANI A, MARCACCI M. (2012b) Second-generation arthroscopic autologous chondrocyte implantation for the treatment of degenerative cartilage lesions. Knee Surg Sports Traumatol Arthrosc 20:1704-1713.

FUENTES-BOQUETE I, LÓPEZ-ARMADA MI, MANEIRO E, FERNÁNDEZSUEIRO JL, CARAMES B, GALDO F, DE TORO FJ, BLANCO FJ. (2004) Pig chondrocyte xenoimplants for human chondral defect repair: an in vitro model. Wound Repair Regen 12:444-452.

GARDNER OF, ARCHER CW, ALINI M, STODDART MJ. (2013) Chondrogenesis of mesenchymal stem cells for cartilage tissue engineering. Histol Histopathol 28:23-42.

GOMOLL AH. (2012) Microfracture and augments. J Knee Surg 25:9-15.

GROSS AE, SHASHA N, AUBIN P. (2005) Long-term followup of the use of fresh osteochondral allografts for posttraumatic knee defects. Clin Orthop Relat Res 79-87.

HANDSCHEL JG, DEPPRICH RA, KUBLER NR, WIESMANN HP, OMMERBORN M, MEYER U. (2007) Prospects of micromass culture technology in tissue engineering. Head Face Med 3:4.

HANGODY L, KISH G, KARPATI Z, SZERB I, UDVARHELYI I. (1997) Arthroscopic autogenous osteochondral mosaicplasty for the treatment of femoral condylar articular defects. A preliminary report. Knee Surg Sports Traumatol Arthrosc 5:262-267.

HANGODY L, RATHONYI GK, DUSKA Z, VASARHELYI G, FULES P, MODIS L. (2004) Autologous osteochondral mosaicplasty. Surgical technique. J Bone Joint Surg Am 86-A Suppl 1:65-72.
HANGODY L, VASARHELYI G, HANGODY LR, SUKOSD Z, TIBAY G, BARTHA L, BODO G. (2008) Autologous osteochondral grafting-technique and long-term results. Injury 39 Suppl 1:S32-39.

HU JC, ATHANASIOU KA. (2006) A self-assembling process in articular cartilage tissue engineering. Tissue Eng 12:969-979.

HWANG NS, ZHANG C, HWANG YS, VARGHESE S. (2009) Mesenchymal stem cell differentiation and roles in regenerative medicine. Wiley Interdiscip Rev Syst Biol Med 1: 97-106.

JAISWAL PK, BENTLEY G, CARRINGTON RW, SKINNER JA, BRIGGS TW. (2012) The adverse effect of elevated body mass index on outcome after autologous chondrocyte implantation. J Bone Joint Surg Br 94:1377-1381.

JANG KM, LEE JH, PARK CM, SONG HR, WANG JH. (2013) Xenotransplantation of human mesenchymal stem cells for repair of osteochondral defects in rabbits using osteochondral biphasic composite constructs. Knee Surg Sports Traumatol Arthrosc (in press).

JOHNSON K, ZHU S, TREMBLAY MS, PAYETTE JN, WANG J, BOUCHEZ LC, MEEUSEN S, ALTHAGE A, CHO CY, WU X, ET AL. (2012) A stem cell-based approach to cartilage repair. Science 336:717-721.

JOHNSTONE B, HERING TM, CAPLAN AI, GOLDBERG VM, YOO JU. (1998) In vitro chondrogenesis of bone marrow-derived mesenchymal progenitor cells. Exp Cell Res 238:265-272.

JOHNSTONE B, YOO J. (2001) Mesenchymal cell transfer for articular cartilage repair. Expert Opin Biol Ther 1:915-921.

KAMINSKI MJ, KAMINSKA G, MOSKALEWSKI S. (1980) Species differences in the ability of isolated epiphyseal chondrocytes to hypertrophy after transplantation into the wall of the Syrian hamster cheek pouch. Folia Biol (Krakow) 28:27-36.

KON E, FILARDO G, DI MARTINO A, MARCACCI M. (2012) ACI and MACI. J Knee Surg 25:17-22.

KSIAZEK T, MOSKALEWSKI S. (1983) Studies on bone formation by cartilage reconstructed by isolated epiphyseal chondrocytes, transplanted syngeneically or across known histocompatibility barriers in mice. Clin Orthop Relat Res 233-242.

LEFEBVRE V, BEHRINGER RR, DE CROMBRUGGHE B. (2001) L-Sox5, Sox6 and Sox9 control essential steps of the chondrocyte differentiation pathway. Osteoarthritis Cartilage 9 Suppl A:S69-75.

LEVY-MISHALI M, ZOLDAN J, LEVENBERG S. (2009) Effect of scaffold stiffness on myoblast differentiation. Tissue Eng Part A 15:935-944.

LIU X, MA PX. (2004) Polymeric scaffolds for bone tissue engineering. Ann Biomed Eng 32:477-486.

LIU S, HOU KD, YUAN M, PENG J, ZHANG L, SUI X, ZHAO B, XU W, WANG A, LU S, GUO Q. (2013) Characteristics of mesenchymal stem cells derived from Wharton's jelly of human umbilical cord and for fabrication of non-scaffold tissue-engineered cartilage. J Biosci Bioeng. 27: $\mathrm{S} 1389-1723$

MALEJCZYK J, OSIECKA A, HYC A, MOSKALEWSKI S. (1991) Effect of immunosuppression on rejection of cartilage formed by transplanted allogeneic rib chondrocytes in mice. Clin Orthop Relat Res 266-273.

MITHOEFER K, WILLIAMS RJ 3RD, WARREN RF, POTTER HG, SPOCK CR, JONES EC, WICKIEWICZ TL, MARX RG. (2005) The microfracture technique for the treatment of articular cartilage lesions in the knee. A prospective cohort study. J Bone Joint Surg Am 87:1911-1920.

MOLINA B, RODRÍGUEZ EM, PERUZZO B, CAPRILE T, NUALART F. (2001) Spatial distribution of Reissner's fiber glycoproteins in the filum terminale of the rat and rabbit. Microsc Res Tech 52:552-563.

NIETHAMMER TR, PIETSCHMANN MF, HORNG A, ROSSBACH BP, FICKLSCHERER A, JANSSON V, MULLER PE. (2013) Graft hypertrophy of matrix-based autologous chondrocyte implantation: a two-year follow-up study of NOVOCART 3D implantation in the knee. Knee Surg Sports Traumatol Arthrosc (in press).

NOVOTNY JE, TURKA CM, JEONG C, WHEATON AJ, LI C, PRESEDO A, RICHARDSON DW, REDDY R, DODGE GR. (2006) Biomechanical and magnetic resonance characteristics of a cartilage-like equivalent generated in a suspension culture. Tissue Eng 12:2755-2764.

OFEK G, REVELL CM, HU JC, ALLISON DD, GRANDE-ALLEN KJ, ATHANASIOU KA. (2008) Matrix development in self-assembly of articular cartilage. PLoS One 3:e2795.

OSIECKA-IWAN A, HYC A, JOZWIAK J, KOMAR A, NIDERLA J, MOSKALEWSKI S. (2003) Transplants of rat chondrocytes evoke strong humoral response against chondrocyte-associated antigen in rabbits. Cell Transplant 12:389-398.

PELISSIER A, BOYER P, BOUSSETTA Y, BIERRY G, VAN HILLE W HAMON P, JAEGER JH, MASSIN P. (2013) Satisfactory long-term MRI after autologous chondrocyte implantation at the knee. Knee Surg Sports Traumatol Arthrosc (in press). 
PELTTARI K, LORENZ H, BOEUF S, TEMPLIN MF, BISCHEL O, GOETZKE K, HSU HY, STECK E, RICHTER W. (2008) Secretion of matrix metalloproteinase 3 by expanded articular chondrocytes as a predictor of ectopic cartilage formation capacity in vivo. Arthritis Rheum 58:467-474

PELTTARI K, STECK E, RICHTER W. (2008) The use of mesenchymal stem cells for chondrogenesis. Injury. 39 Suppl 1:S58-65

RAMALLAL M, MANEIRO E, LOPEZ E, FUENTES-BOQUETE I, LÓPEZARMADA MJ, FERNANDEZ-SUEIRO JL, GALDO F, DE TORO FJ, BLANCO FJ. (2004) Xeno-implantation of pig chondrocytes into rabbit to treat localized articular cartilage defects: an animal model. Wound Repair Regen 12:337-345.

RESPONTE DI, ARZI B, NATOLI RM, HU JC, ATHANASIOU KA. (2012) Mechanisms underlying the synergistic enhancement of self-assembled neocartilage treated with chondroitinase-ABC and TGF-beta1. Biomaterials 33:3187-3194.

REVELL CM, ATHANASIOU KA. (2009) Success rates and immunologic responses of autogenic, allogenic, and xenogenic treatments to repair articular cartilage defects. Tissue Eng Part B Rev 15:1-15.

ROGERS BA, DAVID LA, BRIGGS TW. (2010) Sequential outcome following autologous chondrocyte implantation of the knee: a six-year follow-up. Int Orthop 34:959-964.

RUSSLIES M, BEHRENS P, WUNSCH L, GILLE J, EHLERS EM. (2002) A cell-seeded biocomposite for cartilage repair. Ann Anat 184:317-323.

SALZMANN GM, SAH B, SUDKAMP NP, NIEMEYER P. (2013) Clinical outcome following the first-line, single lesion microfracture at the knee joint. Arch Orthop Trauma Surg 133:303-310.

SEKIYA I, LARSON BL, VUORISTO JT, REGER RL, PROCKOP DJ. (2005) Comparison of effect of BMP-2, -4 , and -6 on in vitro cartilage formation of human adult stem cells from bone marrow stroma. Cell Tissue Res 320:269-276.

SICLARI A, MASCARO G, GENTILI C, CANCEDDA R, BOUX E. (2012) A cell-free scaffold-based cartilage repair provides improved function hyaline-like repair at one year. Clin Orthop Relat Res 470:910-919.

SOLHEIM E, HEGNA J, OYEN J, HARLEM T, STRAND T. (2013) Results at 10 to 14 years after osteochondral autografting (mosaicplasty) in articular cartilage defects in the knee. Knee 20:287-290.

STEADMAN JR, BRIGGS KK, RODRIGO JJ, KOCHER MS, GILL TJ, RODKEY WG. (2003a) Outcomes of microfracture for traumatic chondral defects of the knee: average 11-year follow-up. Arthroscopy 19:477-484.
STEADMAN JR, RODKEY WG, BRIGGS KK. (2003b) Microfracture chondroplasty: Indications, techniques, and outcomes. Sports Medicine and Arthroscopy Review 11:236-244.

STECK E, BERTRAM H, ABEL R, CHEN B, WINTER A, RICHTER W. (2005) Induction of intervertebral disc-like cells from adult mesenchymal stem cells. Stem Cells 23:403-411.

TRATTNIG S, BA-SSALAMAH A, PINKER K, PLANK C, VECSEI V, MARLOVITS S. (2005) Matrix-based autologous chondrocyte implantation for cartilage repair: noninvasive monitoring by high-resolution magnetic resonance imaging. Magn Reson Imaging 23:779-787.

VAN DER KRAAN PM, BUMA P, VAN KUPPEVELT T, VAN DEN BERG WB. (2002) Interaction of chondrocytes, extracellular matrix and growth factors: relevance for articular cartilage tissue engineering. Osteoarthritis Cartilage 10:631-637.

VAN SUSANTE JL, BUMA P, SCHUMAN L, HOMMINGA GN, VAN DEN BERG WB, VETH RP. (1999) Resurfacing potential of heterologous chondrocytes suspended in fibrin glue in large full-thickness defects of femoral articular cartilage: an experimental study in the goat. Biomaterials 20:1167-1175.

VON RECHENBERG B, AKENS MK, NADLER D, BITTMANN P, ZLINSZKY K, KUTTER A, POOLE AR, AUER JA. (2003) Changes in subchondral bone in cartilage resurfacing--an experimental study in sheep using different types of osteochondral grafts. Osteoarthritis Cartilage 11:265-277.

WANG L, TRAN I, SESHAREDDY K, WEISS ML, DETAMORE MS. (2009). A comparison of human bone marrow-derived mesenchymal stem cells and human umbilical cord-derived mesenchymal stromal cells for cartilage tissue engineering. Tissue Eng 15:2259-2266.

WHITESIDE RA, JAKOB RP, WYSS UP, MAINIL-VARLET P. (2005) Impact loading of articular cartilage during transplantation of osteochondral autograft. J Bone Joint Surg Br 87:1285-1291.

WIDUCHOWSKI W, WIDUCHOWSKI J, TRZASKA T. (2007) Articular cartilage defects: study of 25,124 knee arthroscopies. Knee 14:177-182.

ZHANG W, CHEN J, ZHANG S, OUYANG HW. (2012) Inhibitory function of parathyroid hormone-related protein on chondrocyte hypertrophy the implication for articular cartilage repair. Arthritis Res Ther 14:221.

ZHENG MH, WILLERS C, KIRILAK L, YATES P, XU J, WOOD D, SHIMMIN A. (2007) Matrix-induced autologous chondrocyte implantation (MACI): biological and histological assessment. Tissue Eng 13:737-746. 
